\title{
Study on drug profile used in common pregnancy influenced issues and its complications
}

\author{
Semmalar G. V. ${ }^{1}{ }^{*}$, Kaviya Anisha S. J. ${ }^{1}$, Terry Sheetal B. ${ }^{1}$, Saravanakumar R. T. ${ }^{1}$, Latha K. ${ }^{2}$
}

${ }^{1}$ Department of Pharmacy, Annamalai University, Annamalai Nagar, Chidambaram, Tamil Nadu, India

${ }^{2}$ Department of Obstetrics and Gynaecology, Rajah Muthiah Medical College and Hospital, Annamalai Nagar, Chidambaram, Tamil Nadu, India

Received: 16 August 2021

Revised: 07 September 2021

Accepted: 09 September 2021

\section{*Correspondence:}

Dr. Semmalar G. V.,

Email: semmalarmalar569@gmail.com

Copyright: ( $)$ the author(s), publisher and licensee Medip Academy. This is an open-access article distributed under the terms of the Creative Commons Attribution Non-Commercial License, which permits unrestricted non-commercial use, distribution, and reproduction in any medium, provided the original work is properly cited.

\section{ABSTRACT}

Background: Pregnancy influenced issues are common among pregnant women treated by medications that causes complication in mother and fetus. The study aims to identify patients with pregnancy influenced issues like gestational diabetes mellitus, gestational hypertension, gastroesophageal reflux disease and anaemia. To assess the drug used pattern along with antibiotic therapy and to observe the above disease related complications.

Methods: A hospital based prospective observational study was conducted at department of obstetrics and gynecology in Rajah Muthiah Medical College and Hospital. Totally 100 patients enrolled and data was collected using data collection form.

Results: Out of 100 patients, high prevalence occurred in 26-30 years of age. Primarily gestational hypertension (39\%), treated with Tab. Labetatol and complications were premature delivery, low birth weight. Anaemia (25\%) cases treated with Tab. Ferrous sulphate, Iron sucrose and Folic Acid, Preterm delivery as complication. Gestational diabetes mellitus (18\%) treated with Metformin and Human Insulin and complications were preterm delivery, maternal obesity, increased child weight. GERD (8\%) treated with Pantoprazole, Ondansetron, Bifilac and complications were weight loss, dehydration, low birth weight. In pre-operative cases, $79 \%$ received antibiotics as monotherapy and $21 \%$ as dual therapy. In post-operative cases, $41 \%$ received antibiotics as monotherapy and $59 \%$ as dual therapy. Metronidazole $(95 \%)$ given in both post and pre- operative conditions.

Conclusions: The present study provides valuable insight about the overall drugs used in pregnancy related diseases and complications arise. We hope our data will make necessary recommendations to all health care professionals and pregnant women to ensure all pregnancy related safety measures were taken.

Keywords: Gestational hypertension, Gestational diabetes mellitus, Gastroesophageal reflux disease, Anaemia, Antibiotics, Complications

\section{INTRODUCTION}

Pregnancy is a special physiological condition, that cause changes in physical, hormonal, metabolic changes, stress, anxiety and certain medication may lead to the pathological diseased condition where the drug treatment is given to reduce the issues that causes pharmacokinetic changes of drug and induce complications in mother and fetus. About $60-70 \%$ are under medical complications and take medication until delivery. Pregnancy symptoms and complications may range from mild to severe that include gestational hypertension, gestational diabetes mellitus, gastroesophageal reflux disease and anaemia.

Gestational hypertension occurs when arteries carrying blood from the heart to the body organs are narrowed and 
causes pressure to increase in the arteries. It occurs after 20 weeks of gestation without proteinuria and resolved after delivery within 12 weeks. The blood pressure more than $140 / 90 \mathrm{mmHg}$ is considered as gestational hypertension. $^{1}$ Main causes are abnormal placental implantation, vasculopathy and inflammatory changes, genetic factor, immunological factors and nutritional factors.

Gestational diabetes mellitus (GDM) is defined as any degree of glucose intolerance with onset or first recognition during pregnancy at 24 to 28 weeks. The definition applies whether insulin or only diet modification is used for treatment and whether or not the condition persists after pregnancy. ${ }^{2}$ It does not exclude the possibility that unrecognized glucose intolerance may have antedated or begun concomitantly with the pregnancy. Main cause for gestational diabetes includes hormones secreted by placenta that are "diabetogenic". Insulin resistance overweight or obese women, gaining too much of weight and some hormones like growth hormone, human placental lactogen, progesterone, corticotropin releasing hormone are the common causes.

Anaemia is the one of the common complications that occur during pregnancy. Normal physiologic changes in pregnancy affect the hemoglobin $(\mathrm{Hb})$, and there is a relative reduction in $\mathrm{Hb}$ concentration. ${ }^{3}$ The hemoglobin $(\mathrm{Hb})$ concentration of less than $11 \mathrm{~g} / \mathrm{dl}(7.45 \mathrm{mmol} / \mathrm{l})$ and a hematocrit of less than $33 \%$ is defined as anaemia in WHO. Some of the causes are nutritional deficiency like folate, iron and vitamin B12 deficiencies, acute or chronic gastrointestinal bleeding/heavy periods, infections like malaria, HIV, chronic diseases like renal, neoplasm, parasites, hemolytic anemia by drugs and congenital.

Gastroesophageal reflux disease (GERD) is describing the effortless retrograde movement of gastric contents into the oesophagus. The passage of refluxed gastric contents into the oral pharynx is known as regurgitation. Presence of structural changes in the esophagus and occurrence of symptoms affecting individuals' quality of life indicate gastroesophageal reflux disease. ${ }^{4}$ In GERD, the symptoms occur during a pregnancy at any time and they often get worse throughout the pregnancy. The hormonal changes cause the digestive system to slow down and cause heartburn commonly in pregnancy. Causes like effect of hormone can decrease esophageal sphincter pressure, enlarge uterus by increased intra-abdominal pressure, prolonged passage of food from intestine by decreased lower esophageal tone and increased progesterone level cause higher relaxation of lower esophageal sphincter.

Based on the above content, research on study on drug profile used in common pregnancy influenced issues and its complication was conducted. Patients with gestational diabetes mellitus, gestational hypertension, gastroesophageal reflux disease and anaemia both out and in patient who visited the Department of Obstetrics and Gynaecology at Rajah Muthiah Medical College and
Hospital every month and who met the inclusion criteria was included in the study.

\section{METHODS}

A prospective observational study was conducted in the Department of Obstetrics and Gynaecology at Rajah Muthiah Medical College and Hospital, Annamalai University, Annamalai Nagar, Chidambaram during the period of six months from November 2019 to April 2020. Patients who attended Obstetrics and Gynaecology outpatient and inpatient department with the complaints of gestational hypertension, gestational diabetes mellitus, anaemia and gastroesophageal reflux disease between second and third trimester and between the age group of 20-40 years were included in the study after obtaining their signed consent form. The patients were given an explanation on the procedure, objective, and benefits of the research before filling up the informed consent.

The data was collected using designed data collection form. Patients with other co-morbidities conditions like stroke, coronary artery disease, chronic hypertension, chronic diabetes mellitus, chronic seizure and asthma, immunosuppressive patients, hormonal disorders and mentally ill patients were not included in the study. Patients who are not willing to participate in this study are under the age group of 20 and above 40 years was excluded.

Recording of complete identity of the patients in the data collection sheet. The information regarding patient's demographic details, medication history, laboratory data and therapeutic management were collected from patient's case sheets only. The following parameters were analysed; biochemical profile such as fasting blood sugar $\{\mathrm{FBS}\}$, randomized blood sugar $\{$ RBS $\}$, post prandial blood sugar $\{\mathrm{PPBS}\}$ and all data around the culture was collected from lab report.

\section{Statistical analysis}

The data was collected and entered in Microsoft excel software 2007 and interpreted by descriptive statistics that was presented to analyse and express the report as counts and percentages in the form of tables, charts and graphs.

\section{RESULTS}

Sample for research included 100 patients who visited both outpatient and inpatient service in Department of Obstetrics and Gynaecology at RMMCH.

\section{Demographic data on the patient's characteristics}

The total population involved in the research were 100 respondents that consisted of the following: $48 \%$ of the respondents aged between $26-30$ years, $26 \%$ aged between 20-25 years, $20 \%$ aged between 31-35 years and 6\% between 36-40 years of age (Table 1). 
Table 1: Age wise distribution of patients.

\begin{tabular}{|c|c|c|}
\hline Age group (years) & $\mathbf{N}$ & $\%$ \\
\hline $20-25$ & 26 & 26 \\
\hline $26-30$ & 48 & 48 \\
\hline 31-35 & 20 & 20 \\
\hline $36-40$ & 6 & 6 \\
\hline
\end{tabular}

\section{Disease wise distribution of patients}

A majority was found to have gestational hypertension (39\%), followed by anaemia (25\%), gestational diabetes mellitus (18\%) and only a few of them had gastroesophageal reflux disease (8\%) (Table 2).

Table 2: Disease wise distribution of patients.

\begin{tabular}{|lll|}
\hline Name of disease & N & $\%$ \\
\hline Gestational hypertension & 39 & 39 \\
\hline Estational diabetes mellitus & 18 & 18 \\
\hline Gdm and ghtn & 10 & 10 \\
\hline $\begin{array}{l}\text { Gastroesophageal reflux } \\
\text { disease }\end{array}$ & 8 & 8 \\
\hline Anaemia & 25 & 25 \\
\hline
\end{tabular}

\section{Distribution of anti-hypertensive agents}

About $56.4 \%$ of pregnant women taking labetalol as a firstline treatment. Other drugs like nifedipine $25.6 \%$ and a combination of both labetalol and nifedipine was given to $18 \%$ of patients (Table 3 ).

Table 3: Distribution of hypertensive agents.

\begin{tabular}{|llll|}
\hline S. no. & Name of drug & N & $\%$ \\
\hline $\mathbf{1}$ & Tab. labetalol & 22 & 56.4 \\
\hline $\mathbf{2}$ & Tab. nifedipine & 10 & 25.6 \\
\hline $\mathbf{3}$ & $\begin{array}{l}\text { Both labetalol and } \\
\text { nifedipine }\end{array}$ & 7 & 18 \\
\hline
\end{tabular}

Table 4: Distribution of oral and injectable hypoglycemic agents.

\begin{tabular}{|lllll|} 
S. no. & $\begin{array}{l}\text { Route of } \\
\text { administration }\end{array}$ & $\begin{array}{l}\text { Name of } \\
\text { drug }\end{array}$ & $\mathbf{N}$ & $\%$ \\
\hline $\mathbf{1}$ & Oral & Metformin & 10 & 100 \\
\hline $\mathbf{2}$ & Injectable & $\begin{array}{l}\text { Human } \\
\text { actrapid }\end{array}$ & 8 & 43 \\
\hline $\mathbf{3}$ & $\begin{array}{l}\text { Human } \\
\text { mixtard }\end{array}$ & 10 & 57 \\
\hline
\end{tabular}

\section{Distribution of oral hypoglycemic agents}

Metformin is the commonly prescribed drug in about $100 \%$ of pregnant women. On the other hand, human actrapid (43\%) and human mixtard (57\%) were given as subcutaneous injections (Table 4).

\section{Distribution of anaemia drugs}

As shown in Table 5, in first and second trimester, the anaemic patients received ferrous sulphate and folic acid $(60 \%)$, inj. iron sucrose $(28 \%)$ and in severe anaemia, blood transfusion was recommended at 6th or 8th month, before surgery and also after surgery if needed.

Table 5: Distribution of drugs in anaemia.

\begin{tabular}{|lll|}
\hline S. no. & Name of drug & $\mathbf{N}(\%)$ \\
\hline $\mathbf{1}$ & $\begin{array}{l}\text { Tab. ferrous sulphate and } \\
\text { folic acid }\end{array}$ & $15(60)$ \\
\hline $\mathbf{2}$ & Inj. iron sucrose & $7(28)$ \\
\hline $\mathbf{3}$ & $\begin{array}{l}\text { Multivitamins and } \\
\text { multiminerals (anofer) }\end{array}$ & $3(12)$ \\
\hline
\end{tabular}

\section{Distribution of drugs in GERD}

About (38\%) of the patients received cap. bifilac as pre and probiotic, pantoprazole $(50 \%)$ and ondansetron (12\%) were used to prevent GERD symptoms like acid reflux, heart burn and vomiting (Table 6).

Table 6: Distribution of drugs used in GERD.

\begin{tabular}{|llll|}
\hline S. no. & Name of drug & $\mathbf{N}$ & $\%$ \\
\hline $\mathbf{1}$ & Tab. ondansetron & 1 & 12 \\
\hline $\mathbf{2}$ & Tab. pantoprazole & 4 & 50 \\
\hline $\mathbf{3}$ & Probiotics (bifilac) & 3 & 38 \\
\hline
\end{tabular}

\section{Distribution of antibiotics}

From Table 7, it can be seen that the commonly prescribed antibiotics as per physician in pregnant women were cefotaxime, gentamycin and ampicillin other antibiotics like ofloxacin, garamycin, amoxicillin were used whenever necessary.

Table 7: List of commonly used antibiotics in patients.

\begin{tabular}{|lll|}
\hline Drugs & $\mathbf{N}$ & $\%$ \\
\hline Cefotaxime & 60 & 60 \\
\hline Ciprofloxacin & 1 & 1 \\
\hline Gentamicin & 22 & 22 \\
\hline Garamycin & 17 & 17 \\
\hline Ampicillin & 30 & 30 \\
\hline Amoxicillin & 16 & 16 \\
\hline Cefixime & 2 & 2 \\
\hline
\end{tabular}

In pre-operative condition, of about $79 \%$ of patients were given mono therapy and $21 \%$ received dual therapy. Drugs like cefotaxime (62\%), amoxicillin $(27 \%)$ and ampicillin (11\%) were commonly prescribed as mono therapy shown in Table 10 whereas cefotaxime and amoxicillin (76\%) and amoxicillin and ampicillin $(24 \%)$ as dual therapy in Table 8. 
Table 8: Distribution of antibiotics as mono therapy and dual therapy in pre-operative condition.

\begin{tabular}{|c|c|c|c|}
\hline Therapy & Drugs & $\mathbf{N}$ & $\%$ \\
\hline \multirow{3}{*}{$\begin{array}{l}\text { Mono } \\
\text { therapy }\end{array}$} & Amoxicillin & 21 & 27 \\
\hline & Ampicillin & 9 & 11 \\
\hline & Cefotaxime & 49 & 62 \\
\hline \multirow{2}{*}{$\begin{array}{l}\text { Dual } \\
\text { therapy }\end{array}$} & $\begin{array}{l}\text { Cefotaxime and } \\
\text { amoxicillin }\end{array}$ & 16 & 76 \\
\hline & $\begin{array}{l}\text { Amoxicillin and } \\
\text { ampicillin }\end{array}$ & 5 & 24 \\
\hline
\end{tabular}

In post-operative condition, dual therapy was mostly given in patients of about $59 \%$ and mono therapy in $41 \%$ of patients. Drugs like cefotaxime (66\%), amoxicillin (7\%), ampicillin $(17 \%)$ and gentamicin $(10 \%)$ were commonly given as mono therapy shown in Table 12 whereas amoxicillin and ampicillin (51\%), ampicillin and gentamicin $(32 \%)$ and ampicillin+ garamycin $(17 \%)$ as dual therapy were given in Table 9.

Table 9: Distribution of antibiotics as mono therapy and dual therapy in post-operative condition.

\begin{tabular}{|llll|}
\hline Therapy & Drugs & N & $\%$ \\
\hline \multirow{4}{*}{$\begin{array}{l}\text { Mono } \\
\text { therapy }\end{array}$} & Amoxicillin & 3 & 7 \\
\cline { 2 - 4 } & Cefotaxime & 27 & 66 \\
\cline { 2 - 4 } & Ampicillin & 7 & 17 \\
\cline { 2 - 4 } & Gentamicin & 4 & 10 \\
\hline \multirow{2}{*}{$\begin{array}{l}\text { Dual } \\
\text { therapy }\end{array}$} & $\begin{array}{l}\text { Ampicillin and } \\
\text { gentamycin }\end{array}$ & 19 & 32 \\
\cline { 2 - 4 } & $\begin{array}{l}\text { Amoxicillin and } \\
\text { ampicillin }\end{array}$ & 30 & 51 \\
\hline & $\begin{array}{l}\text { Ampicillin and } \\
\text { garamycin }\end{array}$ & 10 & 17 \\
\hline
\end{tabular}

\section{Anti-microbial agents}

About $(95 \%)$ of patients received metronidazole in both post- and pre-operative conditions along with other antibiotics to prevent microbial infections. Ornidazole (5\%) was used to treat and prevent protozoal infections, diarrhoea, dysentery and pelvic inflammation disease like inflammation of uterus, fallopian tube, ovaries and pelvic infections in pregnancy.

\section{Distribution of analgesics}

About $70 \%$ of patients were prescribed with tramadol to relieve moderate to severe pain, a combination of both ibuprofen and paracetamol (20\%) and paracetamol (10\%) was also given.

\section{Complications related to the diseases}

Most of the gestational hypertensive patients (11), between 26-36 weeks gave birth to low weight baby and had a preterm delivery. Among Anaemia patients (5), between 3536 week had preterm delivery. In gestational diabetes mellitus (2), between 34 week and 8 month had complications like maternal and foetal obesity, preterm delivery. Patients with both GHTN and GDM (4) had complications like pre-term delivery and low birth weight. In GERD (4), between 28-38-week complications like weight loss, dehydration and low birth weight were observed (Table 10).

Table 10: Recognised pregnancy related complications.

\begin{tabular}{|llll|}
\hline Diseases & Complications & N & $\begin{array}{l}\text { Gestational } \\
\text { period }\end{array}$ \\
\hline Hypertension & $\begin{array}{l}\text { Pre-term } \\
\text { delivery, low } \\
\text { birth weight }\end{array}$ & 11 & 26-36 weeks \\
\hline $\begin{array}{l}\text { Diabetes } \\
\text { mellitus }\end{array}$ & $\begin{array}{l}\text { Pre-term } \\
\text { delivery, } \\
\text { maternal } \\
\text { obesity, } \\
\text { increase in } \\
\text { child weight }\end{array}$ & 2 & $\begin{array}{l}\text { 34 weeks } \\
\text { and } 8 \\
\text { months }\end{array}$ \\
\hline $\begin{array}{l}\text { Both HTN } \\
\text { and GDM }\end{array}$ & $\begin{array}{l}\text { Pre-term } \\
\text { delivery, low } \\
\text { birth weight }\end{array}$ & 4 & 36 weeks \\
\hline Anemia & $\begin{array}{l}\text { Pre-term } \\
\text { delivery }\end{array}$ & 5 & $35-36$ weeks \\
\hline GERD & $\begin{array}{l}\text { Weight loss, } \\
\text { dehydration, } \\
\text { low birth } \\
\text { weight }\end{array}$ & 4 & $28-38$ weeks \\
\hline
\end{tabular}

\section{DISCUSSION}

From our study among 100 patients, it was evident that the greatest number of pregnancy occurred under the age group of 26-30 years (48\%). Most of the complications were occurred in between these age group or above this age group.

Most of the patients had gestational hypertension (39\%) as a primary complication and treated with labetalol. ${ }^{6,11}$ Secondarily, anaemia (25\%) was identified and was treated with FST and folic acid. ${ }^{7,8}$ If needed, iron sucrose and blood transfusion was given. ${ }^{13}$ Tertiarily, (18\%) of pregnant women had gestational diabetes mellitus and they were treated with hypoglycemic agents like human mixtard and metformin hydrochloride. ${ }^{9,12}$ Only a few patients were identified with GERD (8\%) and they were treated with cap. bifilac, ondansetron \& pantoprazole tablets respectively. ${ }^{10}$

In gestational diabetes mellitus patient, the glycemic level was controlled by hypoglycemic agents like Human Mixtard (80\%) which was the mostly prescribed drug and oral hypoglycemic agents like metformin hydrochloride $(100 \%)$ that belongs to biguanides was the mostly prescribed drug. ${ }^{9,12,19}$ In gestational hypertension patients, anti-hypertensive agents like labetalol (56\%) that belongs 
to beta blocker was the mostly prescribed drug. ${ }^{6,11}$ In analgesics, ibuprofen and paracetamol (20\%) and tramadol about $(70 \%)$ belonging to opioids were mostly prescribed. In GERD patient, cap. bifilac (38\%) was given to improve bacterial flora and pantoprazole (50\%), ondansetron (12\%) was given to decrease vomiting and GI symptoms. ${ }^{10}$ On consideration of the haematinics, folic acid tablet was given in second and third trimester. ${ }^{7}$ Iron sucrose transfusion and Ferrous sulphate tablet $(60 \%)$ was given and in severe cases blood transfusion was recommended..$^{8,13}$

Antibiotics table - proper antibiotics was the best way for treating infections. Women with some problems that arise before delivery like fever, bleeding and prior breakage of amniotic sac need antibiotics before surgery as preantibiotics and compulsory after caesarean section as postantibiotics. $^{20}$ our study shows that the commonly prescribed antibiotics by the physician were cefotaxime, amoxicillin, gentamycin and ampicillin.

In pre-operative conditions, about $79 \%$ of patients received mono therapy and $21 \%$ received dual therapy. Drugs like cefotaxime $(62 \%)$ was the commonly prescribed drug in mono therapy and cefotaxime and amoxicillin (76\%) in dual therapy. In post-operative conditions, dual therapy was mostly given in patient of about $59 \%$ and mono therapy in $41 \%$ of patients. Drugs like cefotaxime $(66 \%)$ was commonly given drug in mono therapy and amoxicillin + ampicillin $(51 \%)$ in dual therapy were given.

Metronidazole (95\%), an anti-microbial agent was given in both post- and pre-operative conditions along with other antibiotics to prevent bacterial vaginosis and trichomonas's effectively and offers no teratogenicity. ${ }^{21}$ About $5 \%$ patient received Ornidazole was used to treat and prevent of protozoal infections.

From the above data, some complications identified were Pre-term delivery and low birth weight in gestational hypertension..$^{5,14,15}$ In both gestational hypertension and gestational diabetes mellitus, complications like preterm delivery and low birth weight were observed. ${ }^{10}$ Maternal and foetal obesity, preterm delivery in gestational diabetes mellitus. ${ }^{16}$ Mostly pre-term delivery in anaemia. ${ }^{17}$ Oral dehydration, weight loss, low birth weight was observed in GERD. ${ }^{18}$

On discharge, the patients were advised to take antibiotics to heal wound and prevent secondary infections. Analgesics like paracetamol to relieve pain and supplements like multi-vitamins to improve patient health condition were also included.

Limitations of the study was that patients with other comorbidities conditions like stroke, coronary artery disease, chronic hypertension, chronic diabetes mellitus, chronic seizure and asthma, immunosuppressive patients, hormonal disorders and mentally ill patients were not included in the study. Further, it did not include patients who are not willing to participate in this study are under the age group of 20 and above 40 years was excluded.

\section{CONCLUSION}

In this study, many of the study participant belong to reproductive age $26-30$ years $(48 \%)$ and we have evaluated the drugs used in effective management of those disease like gestational hypertension (39\%) was most predominant, followed by anaemia (25\%), gestational diabetes mellitus (18\%) and gastroesophageal reflux disease $(8 \%)$ occurring in pregnancy in addition to that preoperative and post-operative antibiotics used. Also, we have identified some complications that occurred by the treatment like preterm labour and low birth weight; in addition, maternal and foetus obesity was observed in Gestational diabetes mellitus, dehydration and weight loss in GERD. Hence, it is necessary to educate women who are pregnant about pregnancy related diseases and drug related complications to prevent the incidence. We hope our data will make necessary recommendations to all health care professionals and pregnant women to ensure all pregnancy related safety measures were taken.

\section{ACKNOWLEDGEMENTS}

Our special thanks to Assoc. Prof. Dr. Sangeerani M, Department of Obstetrics and Gynecology, RMMCH, Annamalai University and all the Post Graduate students, Department of Obstetrics and Gynecology, RMMCH, Annamalai University, Annamalai Nagar for their valuable cooperation and suggestions for carryout our work in successful manner.

\section{Funding: No funding sources \\ Conflict of interest: None declared \\ Ethical approval: The study was approved by the Institutional Ethics Committee}

\section{REFERENCES}

1. Mammaro A, Carrara S, Cavaliere A, Ermito S, Dinatale A, Pappalardo EM, et al. Hypertensive disorders of pregnancy. J Prenat Med. 2009;3(1):1-5.

2. Gestational Diabetes Mellitus. Available at: https://care.diabetesjournals.org/content/26/suppl_1/s 103.

3. Sifakis S, Pharmakides G. Anemia in pregnancy. Ann N Y Acad Sci. 2000;900:125-36.

4. Goral V. Ideal Approach to Gastroesophageal Reflux in Pregnancy. Mathews J Gastroenterol Hepatol. 2018;3(1):11.

5. Mustafa R, Ahmed S, Gupta A, Venuto RC. A comprehensive review of hypertension in pregnancy. J Pregnancy. 2012;2012:105918.

6. Plouin PF, Bréart G, Maillard F, Papiernik E, Relier JP. Maternal effects and perinatal safety of labetalol in the treatment of hypertension in pregnancy. Arch Mal Coeur Vaiss. 1987;80(6):952-5. 
7. Gao Y, Sheng C, Xie RH, Sun W, Asztalos E, Moddemann D, et al. New Perspective on Impact of Folic Acid Supplementation during Pregnancy on Neurodevelopment/Autism in the Offspring Children - A Systematic Review. PLoS One. 2016;11(11):e0165626.

8. Milman N. Oral iron prophylaxis in pregnancy: not too little and not too much! J Pregnancy. 2012;2012:514345.

9. Priya G, Kalra S. Metformin in the management of diabetes during pregnancy and lactation. Drugs Context. 2018;7:212523.

10. Law R, Maltepe C, Bozzo P, Einarson A. Treatment of heartburn and acid reflux associated with nausea and vomiting during pregnancy. Can Fam Physician. 2010;56(2):143-4.

11. Kattah AG, Garovic VD. The management of hypertension in pregnancy. Adv Chronic Kidney Dis. 2013;20(3):229-39.

12. Bhattacharyya A, Brown S, Hughes S, Vice PA. Insulin lispro and regular insulin in pregnancy. QJM. 2001;94(5):255-60.

13. Kriplani A, Mahey R, Dash BB, Kulshreshta V, Agarwal N, Bhatla N. Intravenous iron sucrose therapy for moderate to severe anaemia in pregnancy. Indian J Med Res. 2013;138(1):78-82.

14. Zhang J, Villar J, Sun W, Merialdi M, Abdel-Aleem $\mathrm{H}$, Mathai M, et al. Blood pressure dynamics during pregnancy and spontaneous preterm birth. Am J Obstet Gynecol. 2007;197(2):162.e1-6.
15. Barton JR, O'brien JM, Bergauer NK, Jacques DL, Sibai BM. Mild gestational hypertension remote from term: progression and outcome. Am J Obstet Gynecol. 2001;184(5):979-83.

16. Harper LM, Tita A, Biggio JR. The institute of medicine guidelines for gestational weight gain after a diagnosis of gestational diabetes and pregnancy outcomes. Am J Perinatol. 2015;32(3):239-46.

17. Yi SW, Han YJ, Ohrr H. Anemia before pregnancy and risk of preterm birth, low birth weight and smallfor-gestational-age birth in Korean women. Eur J Clin Nutr. 2013;67:337-42.

18. Jennings LK, Krywko DM. Hyperemesis Gravidarum. 2021. In: StatPearls [Internet]. Treasure Island (FL): StatPearls Publishing; 2021.

19. Hyer S, Balani J, Shehata H. Metformin in Pregnancy: Mechanisms and Clinical Applications. Int J Mol Sci. 2018;19(7):1954.

20. Martinez de Tejada B. Antibiotic use and misuse during pregnancy and delivery: benefits and risks. Int J Environ Res Public Health. 2014;11(8):7993-8009.

21. Sheehy O, Santos F, Ferreira E, Bérard A. "The Use of Metronidazole During Pregnancy: A Review of Evidence", Current Drug Safety. 2015;10(2);15-9.

Cite this article as: Semmalar GV, Kaviya Anisha SJ, Terry Sheetal B, Saravanakumar RT, Latha K. Study on drug profile used in common pregnancy influenced issues and its complications. Int J Basic Clin Pharmacol 2021;10:1196-201. 